\title{
Clinical application of chromosomal microarray analysis for fetuses with craniofacial malformations
}

\author{
Chenyang $\mathrm{Xu}^{1 \dagger}$, Yanbao Xiang ${ }^{1 \dagger}$, Xueqin Xu${ }^{1}$, Lili Zhou ${ }^{1}$, Huanzheng $\mathrm{Li}^{1}$, Xueqin Dong ${ }^{1}$ and Shaohua Tang ${ }^{1,2^{*}}$
}

\begin{abstract}
Background: The potential correlations between chromosomal abnormalities and craniofacial malformations (CFMs) remain a challenge in prenatal diagnosis. This study aimed to evaluate 118 fetuses with CFMs by applying chromosomal microarray analysis (CMA) and G-banded chromosome analysis.

Results: Of the 118 cases in this study, 39.8\% were isolated CFMs (47/118) whereas 60.2\% were non-isolated CFMs (71/118). The detection rate of chromosomal abnormalities in non-isolated CFM fetuses was significantly higher than that in isolated CFM fetuses (26/71 vs. $7 / 47, p=0.01)$. Compared to the 16 fetuses $(16 / 104 ; 15.4 \%)$ with pathogenic chromosomal abnormalities detected by karyotype analysis, CMA identified a total of 33 fetuses (33/118; 28.0\%) with clinically significant findings. These 33 fetuses included cases with aneuploidy abnormalities (14/118; $11.9 \%)$, microdeletion/microduplication syndromes (9/118; 7.6\%), and other pathogenic copy number variations (CNVs) only (10/118; 8.5\%).We further explored the CNV/phenotype correlation and found a series of clear or suspected dosage-sensitive CFM genes including TBX1, MAPK1, PCYT1A, DLG1, LHX1, SHH, SF3B4, FOXC1, ZIC2, CREBBP, SNRPB, and CSNK2A1.
\end{abstract}

Conclusion: These findings enrich our understanding of the potential causative CNVs and genes in CFMs. Identification of the genetic basis of CFMs contributes to our understanding of their pathogenesis and allows detailed genetic counselling.

Keywords: Chromosomal microarray analysis, Craniofacial malformation, Prenatal diagnosis

\section{Background}

Craniofacial malformations (CFMs) are among the most common congenital birth malformations in humans, with orofacial clefts accounting for approximately $13 \%$ of congenital malformations in all live births [1]. The majority of CFMs occur in fetuses without a family history. Thus, it is particularly important to evaluate the integrity of the craniofacial structures of fetuses using ultrasonographic screening. Generally, fetal CFMs

\footnotetext{
*Correspondence: tsh006@126.com

${ }^{+}$Chenyang $\mathrm{Xu}$ and Yanbao Xiang contributed equally to this work.

${ }^{1}$ Center of Prenatal Diagnosis, Wenzhou Central Hospital, Wenzhou, China

${ }^{2}$ Key Laboratory of Medical Genetic, School of Laboratory Medicine and Life Science, Wenzhou Medical University, Wenzhou, China
}

include defects such as cranial malformations, ocular malformations, nasal dysplasia, and orofacial defects, among others. These defects may be isolated variations or may occur in combination with other congenital structural abnormalities such as central nervous system abnormalities, cardiac defects, abdominal wall defects, skeletal defects, and so on. Due to the similar phenotypes of craniofacial syndromes with and without multiple organ involvement, prenatal genetic counseling can be challenging. Although the causes of CFMs are currently unclear, genetic analysis can help to provide a genetic basis for prenatal diagnosis and can also contribute to our understanding of the pathogenesis of CFMs. 
Conventional karyotyping is the classic method for detecting aneuploidy or chromosomal rearrangements [2, 3]. However, this approach has gradually been replaced by chromosomal microarray analysis (CMA) due to its low resolution and low detection efficiency. Recently, CMA has been recommended for prenatal diagnosis when fetal abnormalities are detected by ultrasound [4]. Copy number variations (CNVs) in simple cranial or facial malformations have also been reported [5, 6]; however, the comprehensive CMA assessment of fetuses with CFMs is limited. In the present study, we reviewed the clinical and molecular findings of 118 fetuses with CFMs to explore the clinical significance of CNVs in each case. This study aimed to provide useful information for prenatal diagnosis of CFMs and related genetic counseling.

\section{Results}

\section{Fetal ultrasound findings}

As shown in Table 1, CFMs, including cranial malformations (41,34.7\%), orofacial clefts $(44,37.3 \%)$, ocular and orbital malformations (6, 5.1\%), nasal deformities (5, 4.2\%), ear abnormalities (3, 2.5\%), macroglossia (1, $0.8 \%)$, micrognathia $(1,0.8 \%)$, and complex CFMs $(17,14.4 \%)$ were observed in 118 fetuses. Complex CFMs refer to abnormalities involving two or more different cranial or facial features. Of these 118 cases, $47(39.8 \%)$ were isolated CFMs while $71(60.2 \%)$ were non-isolated CFMs.

\section{Conventional G-banded cytogenetic analysis findings}

Samples for karyotype analysis were obtained from 104 fetuses (40 samples from amniocentesis and 64 samples from cordocentesis); another 14 samples obtained from aborted fetuses were excluded. Successful karyotyping results indicated that $16(16 / 104 ; 15.4 \%)$ fetuses had chromosomal abnormalities; 11 cases showed aneuploidy including trisomy $13(n=$ 5), trisomy $18(n=4)$, trisomy $21(n=1)$, and mosaicism 45 , $\mathrm{X}[32] / 46, \mathrm{XY}[3](n=1)$. Another 5 cases showed chromosomal structural aberrations: 46,XN,der(13)t(4;13)(q35;q31), $46, \mathrm{XN}, \operatorname{der}(13) \mathrm{t}(13 ; 16)(\mathrm{q} 32 ; \mathrm{q} 23), \quad 46, \mathrm{XN}, \operatorname{del}(7)(\mathrm{q} 34), 46, \mathrm{XN}$, rec(6)dup(6q)inv(6)(p25q22), and 45,XN,der(14)t(14;20)(p13; p11.2),-20[17]/46,XN[17].

\section{CMA findings}

An interpretable CMA profile was obtained for all 118 tested genomic DNA samples. Clinically significant results were found in 33 cases $(33 / 118 ; 28.0 \%)$, including 14 cases $(14 / 118 ; 11.9 \%)$ with chromosomal aneuploidies and 19 cases $(19 / 118 ; 16.1 \%)$ with Pathogenic (P) or Likely Pathogenic (LP) CNVs.

In the 14 cases with CMA results indicating chromosomal aneuploidies, 6 fetuses had trisomy 13, 5 fetuses had trisomy 18 , one fetus had trisomy 21 , one fetus had monosomy $\mathrm{X}$, and one fetus had mosaic copy gain of the

Table 1 Phenotypic characteristics of 118 fetuses with CFMs

\begin{tabular}{|c|c|c|c|}
\hline Abnormalities & Isolated CFM (N) & Non-isolated CFM (N) & Referred cases $(\mathrm{N}$ \\
\hline Cranial malformations & & & $41(34.7 \%)$ \\
\hline Microcephaly & 5 & 4 & 9 \\
\hline Macrocephaly & 1 & 5 & 6 \\
\hline Defect in the skull bone & 0 & 13 & 13 \\
\hline Abnormal skull shape & 3 & 10 & 13 \\
\hline Orofacial clefts & & & $44(37.3 \%)$ \\
\hline cleft lip & 6 & 4 & 10 \\
\hline cleft palate & 0 & 1 & 1 \\
\hline cleft lip and palate & 19 & 14 & 33 \\
\hline Ocular and orbital malformations & & & $6(5.1 \%)$ \\
\hline Hypertelorism & 0 & 3 & 3 \\
\hline Hypotelorism & 0 & 2 & 2 \\
\hline Microphthalmia, Cataract & 0 & 1 & 1 \\
\hline Nasal deformity & 5 & 0 & $5(4.2 \%)$ \\
\hline Ear abnormality & 2 & 1 & $3(2.5 \%)$ \\
\hline Macroglossia & 0 & 1 & $1(0.8 \%)$ \\
\hline Micrognathia & 1 & 0 & $1(0.8 \%)$ \\
\hline Complex CFMs & 5 & 12 & 17 (14.4\%) \\
\hline Total & 47 (39.8\%) & $71(60.2 \%)$ & $118(100 \%)$ \\
\hline
\end{tabular}

CFM craniofacial malformation 
$\mathrm{X}$ chromosome in approximately $20 \%$ of cells (Table 2 ). Of the 19 cases with P/LP CNVs, we identified 9 fetuses (9/118; 7.6\%) with CNVs related to known microdeletion or microduplication syndromes (MMSs). These included 22q11 deletion syndrome $(n=3), 22 q 11$ duplication syndrome $(n=1), 7 \mathrm{q} 11.23$ duplication syndrome $(n=1), 3 \mathrm{q} 29$ microdeletion syndrome $(n=1), 16 \mathrm{p} 11.2$ microduplication syndrome $(n=1)$, renal cysts and diabetes syndrome $(n=$ $1)$, and 8p23.1 duplication syndrome $(n=1)$. In addition to MMSs, we identified a further 20 pathogenic CNVs from 11 fetuses. These CNVs involved deletions of 1q21, 4q32q35, 6p25p25, 7q34q36, 11q24q25, 13q31q34, 20p13p11, and Xq26q28, and duplications of 4q32q35, 4q35, 6q22q25, 6q25q27, 7p22p21, 8p23p23, 8p23, 16q23q24, and 16p13p13 (Table 3 and Fig. 1). Among these cases, fetus 23 was found to have $8 \mathrm{p} 23.1$ duplication syndrome combined with another 4 pathogenic CNVs.

All 33 fetuses identified to have P/LP CNVs were terminated in pregnancy or died in utero. Additionally, we found that $9(9 / 118 ; 7.6 \%)$ fetuses that had variant of unknown significance CNVs. The remaining 76 cases $(76 / 118 ; 64.4 \%)$ had no CMA abnormalities or only likely benign/benign CNVs.

\section{Identification of CFM-associated CNVs and genes}

We further analyzed the associations between CFMs and these CNVs and identified the potential candidate genes within these regions. We screened several dosagesensitive or suspected dosage-sensitive genes, including genes TBX1 (22q11.21), MAPK1 (22q11.22), PCYT1A (3q29), and DLG1 (3q29) related to cleft lip/palate,
LHX1 (17q12) related to macrocephaly, SF3B4 (1q21.2) related to micrognathia, FOXC1 (6p25.3) related to ocular hypertelorism and midfacial hypoplasia, ZIC2 (13q32.3) related to cleft lip/palate and abnormal skull shape, SHH (7q36.3) related to multiple CFMs, CREBBP (16p13.3) related to complex CFMs, and $S N R P B$ or CSNK2A1 (20p13) related to microcephaly.

\section{Comparison of chromosomal abnormality detection rates}

Overall, as shown in Table 4, the detection rate of chromosomal abnormalities in non-isolated CFM fetuses was significantly higher than in isolated CFM fetuses (26/71 vs. $7 / 47 ; p=0.01)$. However, there was no significant difference in the chromosomal abnormality detection rate of complex CFMs compared to simple CFMs (6/17 vs. $27 / 101 ; p>0.05)$.

\section{Discussion}

Craniofacial anomalies are common in postnatal cases, especially in patients with nervous system disorders. The detection rate of prenatal cranial abnormalities is unclear; however, there is a high incidence of cranial abnormalities in neonates [7]. Nicolaides et al. (1993) reported a 7\% incidence of facial defects in fetal malformations [8], of which orofacial clefts were the most common, with a prevalence of approximately 1 case per 700 deliveries [9]. In this study, it was observed that cranial abnormalities and orofacial clefts were most common, accounting for 40.6 and $43.6 \%$ of cases, respectively. This finding is consistent with the above reports.

Table 2 CFMs fetuses with chromosomal aneuploidy abnormalities identified by CMA and karyotype analysis

\begin{tabular}{lllll}
\hline Case & Karyotype & CMA results & Craniofacial malformations & Other malformations \\
\hline 1 & $47, X N,+13$ & $\operatorname{arr}(13) \times 3$ & CLP & Gallbladder enlargement; ES; Hyperechogenic kidneys; \\
2 & $47, X N,+13$ & $\operatorname{arr}(13) \times 3$ & Microphthalmia, CLP & Gallbladder enlargement; DW; Hyperechogenic kidneys \\
3 & $47, X N,+13$ & $\operatorname{arr}(13) \times 3$ & Abnormal skull shape, CLP & HPE, DK, TOF \\
4 & $47, X N,+13$ & $\operatorname{arr}(13) \times 3$ & Lemon-shaped skull & Bilateral cerebral ventriculomegaly; SB \\
5 & $47, X N,+13$ & $\operatorname{arr}(13) \times 3$ & CLP & - \\
6 & $N A$ & $\operatorname{arr}(13) \times 3$ & Skull defect & Encephalocele \\
7 & $47, X N,+18$ & $\operatorname{arr}(18) \times 3$ & Abnormal skull shape & HPE; absent radius; VSD; SUA \\
8 & $47, X N,+18$ & $\operatorname{arr}(18) \times 3$ & Microtia, Abnormal pinna & CHD, CH, abnormal hand posture, SUA, polyhydramnios \\
9 & $N A$ & $\operatorname{arr}(18) \times 3$ & Midface depression & Limb body wall complex \\
10 & $47, X N,+18$ & $\operatorname{arr}(18) \times 3$ & CLP & CPC; VSD \\
11 & $47, X N,+18$ & $\operatorname{arr}(18) \times 3$ & Strawberry-shaped skull & Overlapping hands, CPC, LPCM, SUA \\
12 & $47, X N,+21$ & $\operatorname{arr}(21) \times 3$ & Abnormal skull shape & - \\
13 & $45, X[32] / 46, X Y[3]$ & $\operatorname{arr}(\mathrm{X}) \times 1$ & CL & - \\
14 & $N \mathrm{NA}$ & $\operatorname{arr}(\mathrm{X}) \times 1 \sim 2,(\mathrm{Y}) \times 1$ & Skull defect & Anencephaly; Enlarged bladder
\end{tabular}

CFM craniofacial malformation, $C H$ cerebral hernia, $C H D$ complex congenital heart disease, $C L P$ cleft lip and palate, $C L$ cleft lip, $C M A$ chromosomal microarray analysis, CPC choroid plexus cysts, DK duplex kidney, DWM Dandy-Walker malformation, ES esophageal stenosis, HPE Holoprosencephaly, LPCM low placed conus medullaris, SB Spina bifida, SUA single umbilical artery, TOF tetralogy of Fallot, VSD ventricular septal defect; XN, XX or XY 


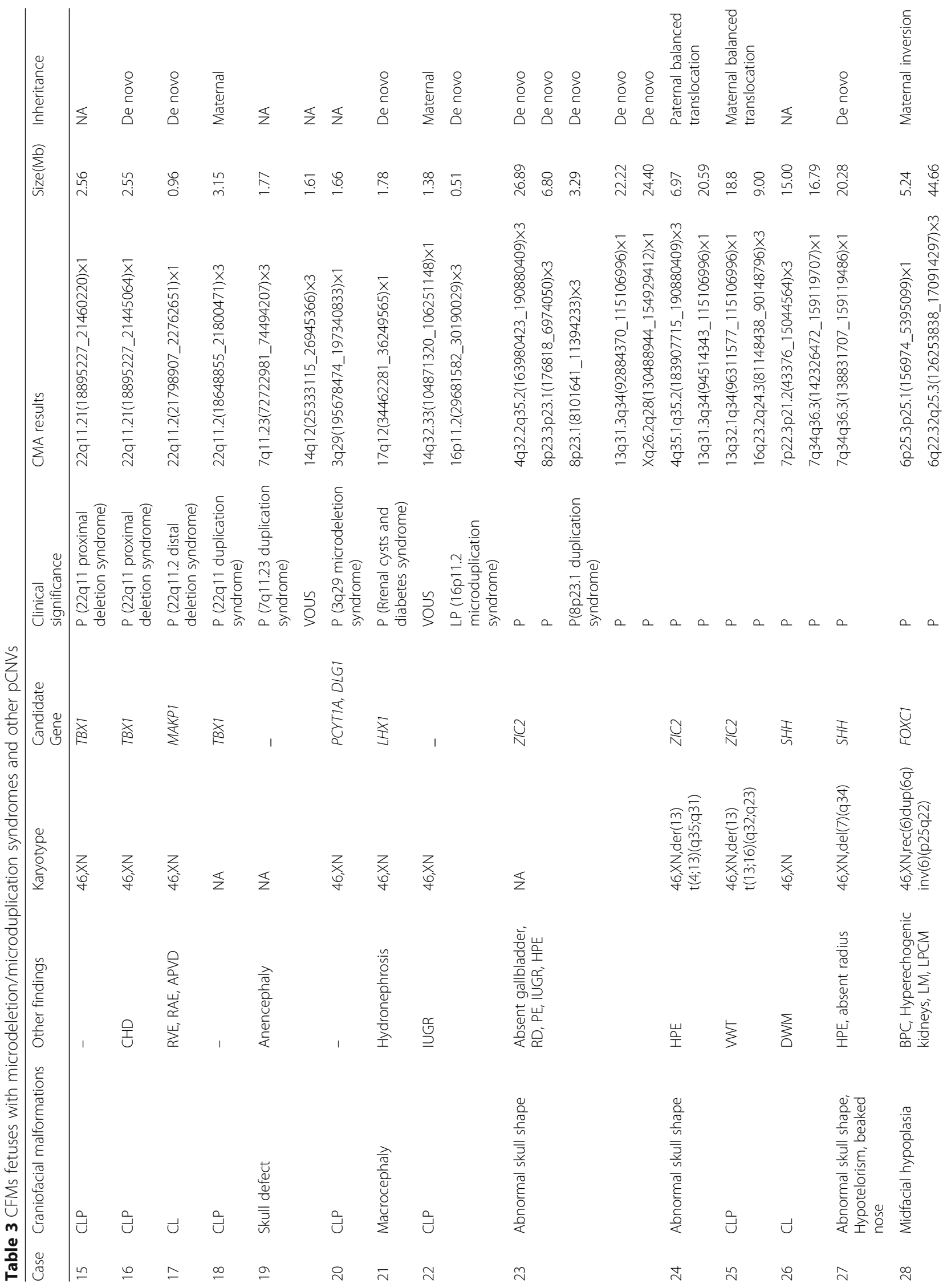


Xu et al. Molecular Cytogenetics

(2020) 13:38

Page 5 of 9

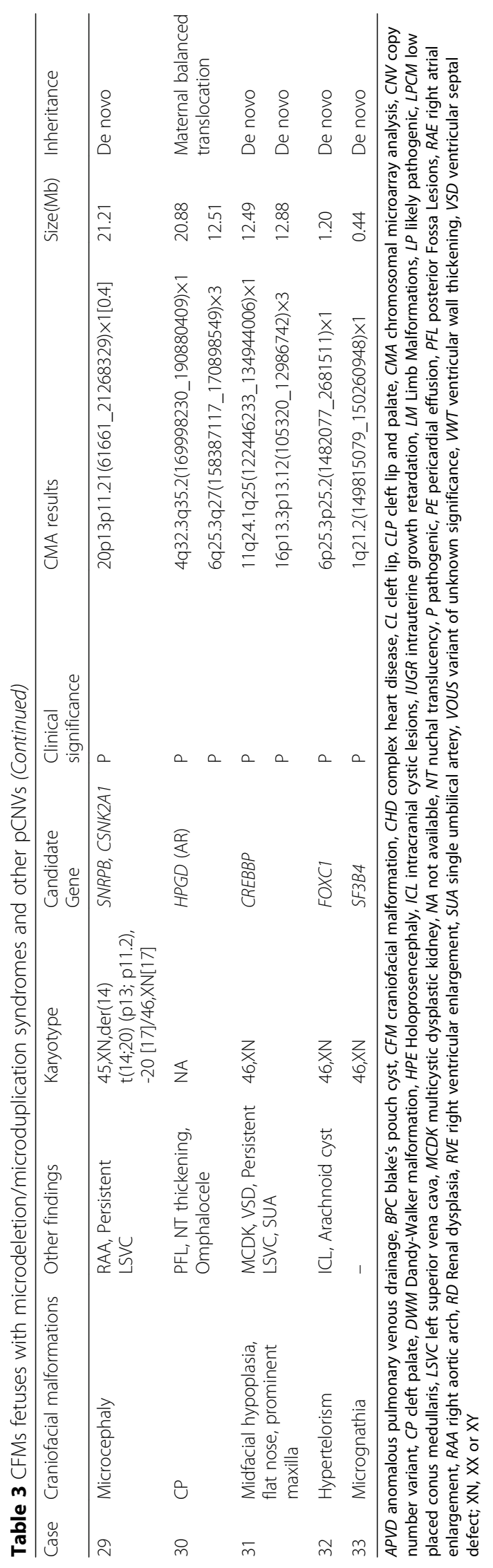



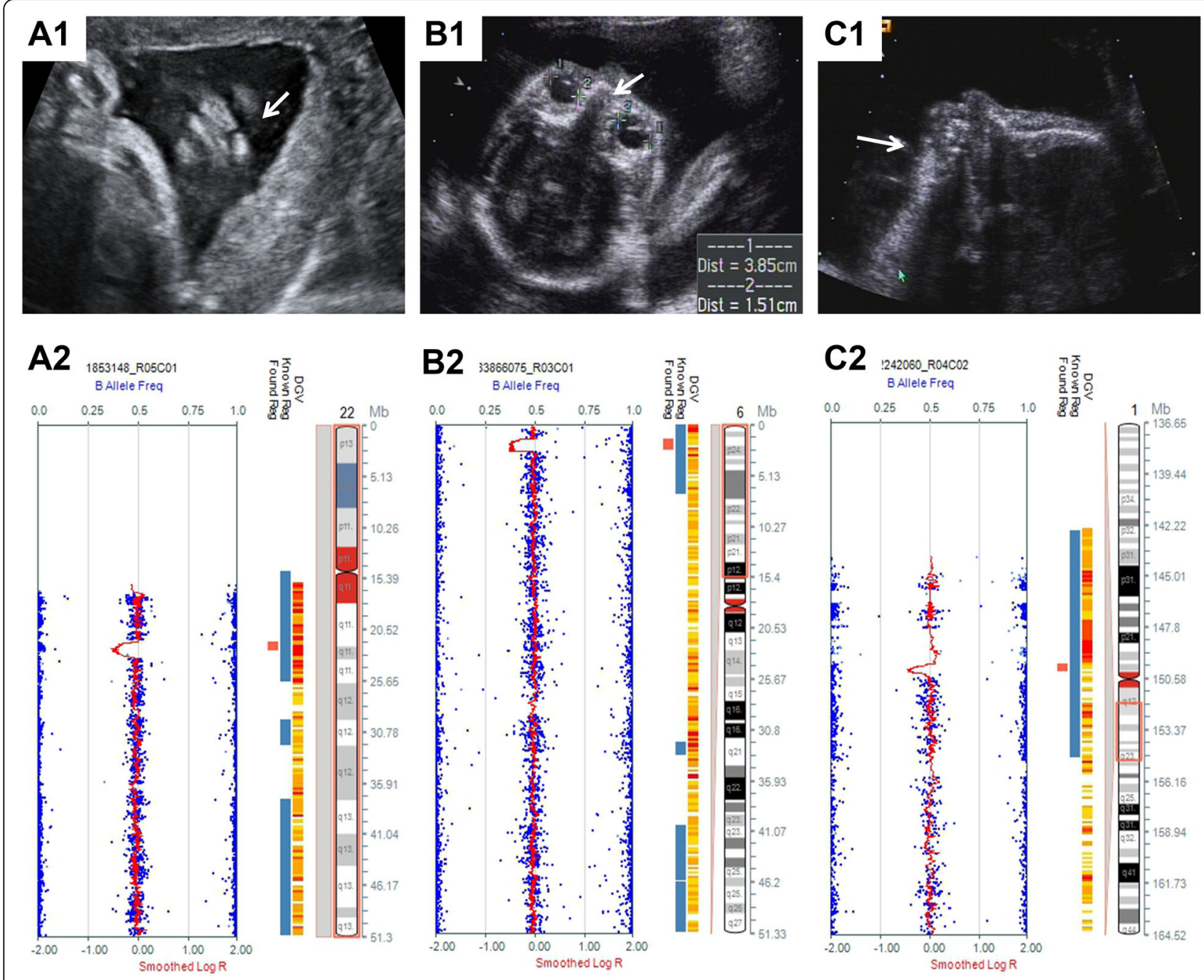

Fig. 1 Abnormal ultrasonographic findings and the identified pCNVs of three selected fetuses. a A $0.96 \mathrm{Mb}$ deletion related to $22 \mathrm{q} 11.2$ distal deletion syndrome (A2) was identified in fetus 17 with cleft lip (A1). b A $1.20 \mathrm{Mb}$ deletion of 6p25.3p25.2 (B2) was identified in fetus 32 with hypertelorism (B1). c A $0.44 \mathrm{Mb}$ deletion of 1q21.11q21.2 (C2) was identified in fetus 33 with micrognathia (C1)

CMA offers obvious advantages in improving the detection rate and identifying the pathogenicity of CNVs. Recently, there have also been several successive research publications on prenatal diagnosis of fetal cleft lip/palate and cranial anomalies with the use of CMA $[5,6]$. In our study, cytogenetic karyotyping revealed abnormal karyotypes in $15.4 \%$ of fetuses and the detection rate increased by $12.6 \%$ with CMA. The incidence of chromosomal aberrations and CNVs was significantly higher than the 4.6 and $6.3 \%$, respectively, reported in a recent study of fetal structural abnormalities [10]. The reason for the discrepancies between previous reports $[10,11]$ and our study is that we did not merely focus on isolated CFMs or cases with simple CFMs.

Table 4 Detection rate of clinically significant chromosomal aberrations in fetuses with various CFMs

\begin{tabular}{|c|c|c|c|c|c|c|c|c|c|}
\hline \multirow[t]{2}{*}{ Malformation } & \multicolumn{7}{|l|}{ Simple CFMs } & \multirow{2}{*}{$\begin{array}{l}\text { Complex } \\
\text { CFMs } \\
(\mathrm{n} / \mathrm{N})\end{array}$} & \multirow{2}{*}{$\begin{array}{l}\text { Referred } \\
\text { cases } \\
(\mathrm{n} / \mathrm{N}, \%)\end{array}$} \\
\hline & $\begin{array}{l}\text { Cranial } \\
\text { malformation } \\
(\mathrm{n} / \mathrm{N})\end{array}$ & $\begin{array}{l}\text { Orofacial } \\
\text { cleft }(n / N)\end{array}$ & $\begin{array}{l}\text { Nasal } \\
\text { deformity } \\
(\mathrm{n} / \mathrm{N})\end{array}$ & $\begin{array}{l}\text { Ocular } \\
\text { malformation } \\
(\mathrm{n} / \mathrm{N})\end{array}$ & $\begin{array}{l}\text { Ear } \\
\text { abnormality } \\
(\mathrm{n} / \mathrm{N})\end{array}$ & $\begin{array}{l}\text { Macroglossia } \\
(\mathrm{n} / \mathrm{N})\end{array}$ & $\begin{array}{l}\text { Micrognathia } \\
(\mathrm{n} / \mathrm{N})\end{array}$ & & \\
\hline Isolated CFMs & $1 / 9$ & $5 / 25$ & $0 / 5$ & $0 / 0$ & $0 / 2$ & $0 / 0$ & $1 / 1$ & $0 / 5$ & $7 / 47,14.9 \%$ \\
\hline Non-isolated CFMs & $10 / 32$ & $8 / 19$ & 0/0 & $1 / 6$ & $1 / 1$ & $0 / 1$ & 0/0 & $6 / 12$ & $26 / 71,36.6 \%$ \\
\hline Total & $11 / 41$ & $13 / 44$ & $0 / 5$ & $1 / 6$ & $1 / 3$ & $0 / 1$ & $1 / 1$ & $6 / 17$ & $33 / 118,28.0 \%$ \\
\hline
\end{tabular}

CFM craniofacial malformation 
In this study, we attempted to determine the potential correlation between CNVs and CFMs in fetuses using CMA. This study identified 9 cases (cases 15-23) with CNVs relating to known chromosomal MMSs, of which 22q11 deletion/duplication syndrome was the most common, with an overall prevalence of $3.4 \%$ (4/118; 2 proximal deletion, 1 proximal duplication, and 1 distal deletion). 22q11 proximal deletion, also known as DiGeorge syndrome or velocardiofacial syndrome, involves more than 30 Mendelian genes; potential genes such as TBX1, COMT, UFD1L, GNB1L, TRXR2, MED15, and RANBP1 were researched to explore the phenotype/ $\mathrm{CNV}$ correlation. Cleft palate is among the most common problems in patients with this microdeletion, while simple cleft lip is only occasionally found [12]. According to previous reports, $T B X 1$ is considered to be responsible for cleft lip/palate phenotypes in both 22q11 deletion and 22q11 duplication [13]. Fetus 17, with heart abnormalities and cleft lip, was found to carry 22q11 distal deletion syndrome. Heart problems are a usual finding, but cleft lip only, without cleft palate, has never been reported within the clinical spectrum of this syndrome. This suggests that simple cleft lip may need to be included in the phenotype spectrum of 22q11 distal deletion syndrome. Although researchers such as Spineli-Silva argue that the cause of CHDs and craniofacial anomalies in patients with distal 22q11 deletion may be haploinsufficient MAPK1 expression [14], the underlying mechanisms are still largely unknown.

In addition, we identified five distinct $\mathrm{CNV}$ s associated with rare MMSs, including two microdeletion syndromes (3q29 and 17q12) and three microduplication syndromes (7q11.23, 8p23.1 and 16p11.2). These syndromes are associated with a range of mental and physical disabilities as well as craniofacial abnormalities. We screened several candidate genes located in these regions that are involved in craniofacial development, such as PCYT1A (3q29), [15], DLG1 (3q29), [16]), and LHX1 (17q12), [17, 18]. Although TBX6 is considered to be a key gene resulting in several major phenotypes in 16 p11.2 duplication, potential genes associated with orofacial cleft in this region still require further exploration. Additionally, there is no reported correlation between 7q11.23 duplication and skull defects resulting from anencephaly, but this fragment has been confirmed as a pathogenic $\mathrm{CNV}$ of central nervous system development.

Other rare CNVs detected in the present study are also believed to contribute to the pathogenesis of CFMs. ZIC2 in 13q23.3 (cases 23-25) has been identified as a key gene associated with several major CFMs resulting from holoprosencephaly [19]. Deletion in the chromosome 7q34q36.3-encompassing gene $S H H$ was identified in cases 26 and 27; SHH is involved in the organization and morphology of the developing embryo and is known to be a key gene in craniofacial abnormalities such as microcephaly, hypotelorism, midface hypoplasia, and cleft lip/palate [20]. In case 33 with isolated micrognathia, a $0.44 \mathrm{Mb}$ deletion in region 1q21.1 was identified; haploinsufficiency of gene SF3B4 in 1q21.1 has been confirmed to be associated with micrognathia [21]. Additionally, there is also evidence of the pathogenicity of haploinsufficient FOXC1 expression. Heterozygous deletion of FOXC1 in 6p25.3 (cases 28 and 32) can lead to Axenfeld-Rieger syndrome (6p25 deletion syndrome); ocular hypertelorism and flat midface are prevalent in affected postnatal cases [22].

Case 31, which exhibited a maxillary protrusion, midface hypoplasia, and a flat nose, had a $12.49 \mathrm{Mb}$ deletion in chromosome 11q24.1q25 and a $12.88 \mathrm{Mb}$ duplication in chromosome 16p13.3p13.12 involving the gene CREBBP. There are several literature reports suggesting that duplication of the $16 \mathrm{p} 13.3$ region containing the CREBBP gene results in distinct similar facial dysmorphism [23], but, to date, no cases with duplication only encompassing the CREBBP gene have been reported. Case 29 had microcephaly $<2 \mathrm{SD}$ and had a $21.21 \mathrm{Mb}$ mosaic deletion in chromosome 20p13p11.21. Among 141 protein coding genes within this deletion region, mutations only in SNRPB and CSNK2A1 have been reported to be associated with autosomal dominant microcephaly [24, 25]. However, to date, there is no evidence supporting their pathogenicity in haploinsufficiency. In case 30 , we could not identify a gene specifically associated with the observed cleft palate; we only identified an autosomal recessive gene, HPGD, associated with a higharched palate and without dose-sensitive reports [26]. We suspect a single mutation on the other chromosome may explain the observed phenotype. In the future, the function of candidate genes within the identified CNVs should be further investigated.

\section{Conclusion}

The current findings enrich our understanding of the potential causative CNVs and genes in CFMs. We detected several CNVs, including nine MMS regions associated with CFMs, and found a series of clear or suspected dosage-sensitive CFM genes including $T B X 1$, MAPK1, PCYT1A, DLG1, LHX1, SHH, SF3B4, FOXC1, ZIC2, CREBBP, SNRPB, and CSNK2A1.

\section{Methods}

\section{Study subjects}

The present study was approved by the institutional research ethics committee of our unit. All parents agreed to participate in the study and provided written informed consent. We retrospectively analyzed a cohort of 118 fetuses with CFMs that were diagnosed at the Wenzhou Prenatal Diagnosis Center between 2012 and 
2019. All the pregnant women underwent prenatal ultrasound examination or magnetic resonance imaging performed by experienced maternal fetal medicine specialists and ultrasound technicians. The pregnant women ranged in age from 21 to 43 years, with their gestational week ranging between 13 to 32 weeks. The eligibility conditions for inclusion in this study were isolated CFMs and non-isolated CFMs (with other structural abnormalities or sonographic soft markers). According to the International Society of Ultrasound in Obstetrics and Gynecology (ISUOG) guidelines [27] and the recent detailed ultrasonographic report of prenatal CFMs [28], the CFMs included cranial malformations (such as abnormal size, shape, and integrity of the skull) and various facial structure abnormalities in coronal, transverse, and sagittal planes (such as abnormal number, size, shape, mass, or location of orbits, lens, palpebral fissure, mandible, maxilla, forehead, nose/nostrils, lips, tongue, soft palate, or ears). Of note, nasal bone absence or dysplasia as sonographic soft markers were excluded from the facial malformations. Fetal samples were obtained from aborted fetuses (14 cases) or were collected by amniocentesis (40 cases) or cordocentesis (64 cases) based on the gestational week at the time of invasive prenatal testing.

\section{Karyotype analysis}

A total of 104 fetal samples (14 fetal tissues from abortions were excluded) were analyzed using standard Gbanded karyotyping at 320-450 bands resolution to diagnose overall chromosomal abnormalities. At least 20 metaphase cells from each sample were carefully examined by an experienced technician to detect chromosomal structural abnormalities and numerical abnormalities.

\section{Chromosomal microarray analysis}

CMA was performed on all samples from the 118 cases using the Illumina Human CytoSNP-12 Array or the Affymetrix CytoScan $750 \mathrm{k}$ Array, according to the respective manufacturers' instructions. The results were analyzed with Chromosome Analysis Suite software. All detected CNVs were compared with known CNVs in the scientific literature and in the following publicly available databases: DECIPHER (http://decipher.sanger.ac.uk/ ), Database of Genomic Variants (DGV, http://dgv.tcag. ca/dgv/app/home), Online Mendelian Inheritance in Man (OMIM, http://www.omim.org), ClinGen Dosage Sensitivity Map (https://www.ncbi.nlm.nih.gov/projects/ dbvar/clingen), and International Standards for Cytogenomic Arrays (ISCA, https://www.iscaconsortium.org/).

According to the American College of Medical Genetics Standards and Guidelines, the CNVs were classified as pathogenic, likely pathogenic, benign (B), likely benign (LB), or variant of unknown significance (VOUS) $[29,30]$. Given the reliability of the minimum detection range, the reporting threshold for $\mathrm{P}$ or $\mathrm{LP} \mathrm{CNVs}$ was $100 \mathrm{~Kb}$; LB/B CNVs and VOUS CNVs smaller than 500 $\mathrm{Kb}$ deletion or $1000 \mathrm{~Kb}$ duplication were not reported, consistent with the Canadian College of Medical Geneticists (CCMG)-Society of Obstetricians and Gynaecologists of Canada (SOGC) recommendations [31]. All reported CNVs were according to the National Center for Biotechnology Information human genome build 37 (hg 19). CMA or quantitative real-time polymerase chain reaction was also performed on parental DNA samples, if DNA were available, to determine whether the CNVs detected were inherited or de novo.

To identify CFM-associated CNVs and candidate genes, we further examined and analyzed the genes within identified $\mathrm{CNVs}$ by retrieving related literature and examining related databases.

\section{Statistical analysis}

Statistical analysis was performed with SPSS 23.0 (IBM Corporation, USA). The CMA detection rates of P/LP variants were compared between various isolated and non-isolated CFM fetuses, and simple and complex CFM fetuses; $p<0.05$ was considered statistically significant.

\section{Abbreviations \\ CMA: Chromosomal microarray analysis; CFM: Craniofacial malformation; CNV: Copy number variation; P: Pathogenic; LP: Likely pathogenic; LB: Likely benign; B: Benign; VOUS: Variant of unknown significance; \\ MMS: Microdeletion or microduplication syndrome}

\section{Acknowledgements}

We sincerely thank all of the subjects for their participation and cooperation in this study. In addition, the authors wish to acknowledge the support of clinical geneticists and certified genetic counselors.

\section{Authors' contributions}

C. Y. Xu and S. H. Tang conceived the idea, Y. B. Xiang and X. Q. Dong collected the samples, H. Z. Li and X. Q. Xu performed the experiments, L. L. Zhou and C. Y. Xu performed data analyses, C. Y. Xu and Y. B. Xiang wrote the manuscript. All authors have read and approved the final manuscript.

\section{Funding \\ Medical and Health of Science and Technology Project of Wenzhou, Grant No. Y20190460; Medical and Health of Science and Technology Project of Zhejiang Province support plan (2020KY921); Science and Technology Planning Project of Wenzhou, Grant No. ZS2017004.}

\section{Availability of data and materials}

The data that support the findings of this study are available from the corresponding author upon reasonable request.

\section{Ethics approval and consent to participate}

This research was approved by the Ethics Committee of Wenzhou Central Hospital. It is a retrospective study without any identifiers related to patients. All patients participating in the study gave written informed consent.

Consent for publication

All patients in this study provided their consent for publication. 


\section{Competing interests}

The authors declare no conflicts of interest regarding the publication of this paper.

Received: 15 April 2020 Accepted: 14 July 2020

Published online: 25 August 2020

\section{References}

1. Nazer J, Ramirez MC, Cifuentes L. Evolution of prevalence rates of orofacial clefts in a maternity of a Chilean clinical hospital. Rev Med Chil. 2010;138(5): 567-72 S0034-98872010000500006.

2. Farcaş S, Crişan CD, Andreescu N, Stoian M, Motoc AG. Structural chromosomal anomalies detected by prenatal genetic diagnosis: our experience. Romanian J Morphol Embryol. 2013;54(2):377-83 PMID:23 771085.

3. Neagos D, Cretu R, Sfetea RC, Bohiltea LC. The importance of screening and prenatal diagnosis in the identification of the numerical chromosomal abnormalities. Maedica (Buchar). 2011;6(3):179-84 PMID:22368694

4. American College of Obstetricians and Gynecologists Committee on Genetics. Committee opinion no. 581: the use of chromosomal microarray analysis in prenatal diagnosis. Obstet Gynecol. 2013;122(6):1374-7. https:// doi.org/10.1097/01.AOG.0000438962.16108.d1.

5. Poot M. Structural genome variations related to Craniosynostosis. Mol Syndromol. 2019;10(1-2):24-39. https://doi.org/10.1159/000490480.

6. Conte F, Oti M, Dixon J, et al. Systematic analysis of copy number variants of a large cohort of orofacial cleft patients identifies candidate genes for orofacial clefts. Hum Genet. 2016;135(1):41-59. https://doi.org/10.1007/ s00439-015-1606-x

7. Vargo JD, Hasan A, Andrews BT. Identification and Management of Cranial Anomalies in perinatology. Clin Perinatol. 2018;45(4):699-715. https://doi. org/10.1016/j.clp.2018.07.008

8. Nicolaides KH, Salvesen DR, Snijders RJ, Gosden CM. Fetal facial defects: associated malformations and chromosomal abnormalities. Fetal Diagn Ther. 1993;8(1):1-9. https://doi.org/10.1159/000263740.

9. Dixon MJ, Marazita ML, Beaty TH, Murray JC. Cleft lip and palate: understanding genetic and environmental influences. Nat Rev Genet. 2011; 12(3):167-78. https://doi.org/10.1038/nrg2933.

10. Fu F, Li R, Li Y, Nie ZQ, Lei T, Wang D, et al. Whole exome sequencing as a diagnostic adjunct to clinical testing in fetuses with structural abnormalities. Ultrasound Obstet Gynecol. 2018;51(4):493-502. https://doi.org/10.1002/uog. 18915.

11. Khandelwal KD, van Bokhoven H, Roscioli T, Carels CE, Zhou H. Genomic approaches for studying craniofacial disorders. Am J Med Genet C: Semin Med Genet. 2013;163C(4):218-31. https://doi.org/10.1002/ajmg.c.31379.

12. Bassett AS, Chow EW, Husted J, Weksberg R, Caluseriu O, Webb GD, et al. Clinical features of 78 adults with 22q11 deletion syndrome. Am J Med Genet A. 2005;138(4):307-13. https://doi.org/10.1002/ajmg.a.30984.

13. Yagi H, Furutani $Y$, Hamada H, Sasaki T, Asakawa S, Minoshima S, et al. Role of TBX1 in human del22q11.2 syndrome. Lancet. 2003;362(9393):1366-73. https://doi.org/10.1016/s0140-6736(03)14632-6.

14. Spineli-Silva S, Bispo LM, Gil-da-Silva-Lopes VL, Vieira TP. Distal deletion at 22q11.2 as differential diagnosis in craniofacial Microsomia: case report and literature review. Eur J Med Genet. 2018;61(5):262-8. https://doi.org/10.1016/ j.ejmg.2017.12.013.

15. Chernus J, Roosenboom J, Ford M, Lee MK, Emanuele B, Anderton J, et al. GWAS reveals loci associated with velopharyngeal dysfunction. Sci Rep. 2018;8(1):8470. https://doi.org/10.1038/s41598-018-26880-w.

16. Mostowska A, Gaczkowska A, Żukowski K, Ludwig KU, Hozyasz KK, Wójcicki $P$, et al. Common variants in DLG1 locus are associated with non-syndromic cleft lip with or without cleft palate. Clin Genet. 2018;93(4):784-93. https:// doi.org/10.1111/cge.13141

17. Moreno-De-Luca D, SGENE Consortium, Mulle JG, Simons Simplex Collection Genetics Consortium, Kaminsky EB, Sanders SJ, et al. Deletion 17q12 is a recurrent copy number variant that confers high risk of autism and schizophrenia. Am J Hum Genet. 2010;87(5):618-30. https://doi.org/10.1016/ j.ajhg.2010.10.004.

18. McMahon R, Sibbritt T, Salehin N, Osteil P, Tam PPL. Mechanistic insights from the LHX1-driven molecular network in building the embryonic head. Develop Growth Differ. 2019;61(5):327-36. https://doi.org/10.1111/dgd. 12609.
19. Savastano CP, Bernardi P, Seuánez HN, Moreira MÂ, Orioli IM. Rare nasal cleft in a patient with holoprosencephaly due to a mutation in the ZIC2 gene. Birth Defects Res A Clin Mol Teratol. 2014;100(4):300-6. https://doi.org/10. 1002/bdra.23216.

20. Rosenfeld JA, Ballif BC, Martin DM, Aylsworth AS, Bejjani BA, Torchia BS, et al. Clinical characterization of individuals with deletions of genes in holoprosencephaly pathways by aCGH refines the phenotypic spectrum of HPE. Hum Genet. 2010;127(4):421-40. https://doi.org/10.1007/s00439-0090778-7.

21. Lund IC, Vestergaard EM, Christensen R, Uldbjerg N, Becher N. Prenatal diagnosis of Nager syndrome in a 12-week-old fetus with a whole gene deletion of SF3B4 by chromosomal microarray. Eur J Med Genet. 2016;59(1): 48-51. https://doi.org/10.1016/j.ejmg.2015.12.001.

22. De Vos IJ, Stegmann AP, Webers CA, Stumpel CT. The 6p25 deletion syndrome: an update on a rare neurocristopathy. Ophthalmic Genet. 2017; 38(2):101-7. https://doi.org/10.3109/13816810.2016.1164191.

23. Thienpont B, Béna F, Breckpot J, Philip N, Menten B, Van Esch H, et al. Duplications of the critical Rubinstein-Taybi deletion region on chromosome 16p13.3 cause a novel recognisable syndrome. J Med Genet. 2010;47(3):155-61. https://doi.org/10.1136/jmg.2009.070573.

24. Tooley M, Lynch D, Bernier F, Parboosingh J, Bhoj E, Zackai E, et al. Cerebrocosto-mandibular syndrome: clinical, radiological, and genetic findings. Am J Med Genet A. 2016;170A(5):1115-26. https://doi.org/10.1002/ajmg.a.37587.

25. Chiu ATG, Pei SLC, Mak CCY, Leung GKC, Yu MHC, Lee SL, et al. Okur-Chung neurodevelopmental syndrome: eight additional cases with implications on phenotype and genotype expansion. Clin Genet. 2018;93(4):880-90. https:// doi.org/10.1111/cge.13196.

26. Latos-Bielenska A, Marik I, Kuklik M, Materna-Kiryluk A, Povysil C, Kozlowski K. Pachydermoperiostosis-critical analysis with report of five unusual cases. Eur J Pediatr. 2007;166(12):1237-43. https://doi.org/10.1007/s00431-006-0407-6.

27. Salomon LJ, Alfirevic Z, Berghella V, Bilardo C, Hernandez-Andrade E, Johnsen $S L$, et al. Practice guidelines for performance of the routine midtrimester fetal ultrasound scan. Ultrasound Obstet Gynecol. 2011:37:116-26. https://doi.org/10.1002/uog.8831

28. Mak ASL, Leung KY. Prenatal ultrasonography of craniofacial abnormalities. Ultrasonography. 2019;38(1):13-24. https://doi.org/10.14366/usg.18031.

29. Kearney HM, Thorland EC, Brown KK, Quintero-Rivera F, South ST, Working Group of the American College of Medical GeneticsLaboratory Quality Assurance Committee. American college of medical genetics standards and guidelines for interpretation and reporting of postnatal constitutional copy number variants. Genet Med. 2011;13(7):680-5. https://doi.org/10.1097/GIM. ob013e3182217a3a.

30. South ST, Lee C, Lamb AN, Higgins AW, Kearney HM, Working Group for the American College of Medical Genetics and Genomics Laboratory Quality Assurance Committee. ACMG standards and guidelines for constitutional cytogenomic microarray analysis, including postnatal and prenatal applications: revision 2013. Genet Med. 2013;15(11):901-9. https://doi.org/10. 1038/gim.2013.129.

31. Armour CM, Dougan SD, Brock JA, Chari R, Chodirker BN, DeBie I, et al Practice guideline: joint CCMG-SOGC recommendations for the use of chromosomal microarray analysis for prenatal diagnosis and assessment of fetal loss in Canada. J Med Genet. 2018;55(4):215-21. https://doi.org/10. 1136/jmedgenet-2017-105013.

\section{Publisher's Note}

Springer Nature remains neutral with regard to jurisdictional claims in published maps and institutional affiliations.

Ready to submit your research? Choose BMC and benefit from:

- fast, convenient online submission

- thorough peer review by experienced researchers in your field

- rapid publication on acceptance

- support for research data, including large and complex data types

- gold Open Access which fosters wider collaboration and increased citations

- maximum visibility for your research: over $100 \mathrm{M}$ website views per year

At $\mathrm{BMC}$, research is always in progress.

Learn more biomedcentral.com/submission 